\title{
Economía y mujer en la manualística escolar de la España democrática: análisis comparativo entre el período de la Transición y los primeros años del siglo XXI ${ }^{1}$
}

\author{
Guichot-Reina, Virginia \\ Universidad de Sevilla, Sevilla, España \\ guichot@us.es
}

De la Torre Sierra, Ana María

Universidad de Sevilla, Sevilla, España

anadesie@alum.us.es

\section{Resumen}

A lo largo de los años, los manuales escolares han sido uno de los recursos didácticos más utilizados por el profesorado. El libro escolar es, además de un soporte curricular a través del cual se transmite el conocimiento académico que las instituciones han de propagar, un reflejo de la sociedad que lo produce en cuanto a que en él se vehiculan valores, actitudes, estereotipos e ideologías que caracterizan la mentalidad dominante de una determinada época o, lo que es lo mismo, el imaginario colectivo que configura el currículum explícito, y también el oculto. Dicho imaginario ha sostenido la persistencia de una sociedad patriarcal, en la que la mujer aparece en un lugar secundario con respecto al hombre, y con unos roles prefijados conectados a una visión esencialista de la condición femenina.

Cabría pensar que España, tras el fin de la dictadura franquista, ha experimentado una evolución significativa en la forma de concebir las funciones políticas, económicas y sociales adjudicadas a ambos sexos, intentando evitar desigualdades perniciosas. Dicha evolución debería verse reflejada en los libros de texto que el alumnado maneja en las aulas. A través de este trabajo, y mediante análisis tanto cuantitativo como cualitativo tanto de las imágenes como de los textos verbales, queremos observar si dicha evolución ha existido, sobre todo desde el punto de vista de la denominada "cultura económica», analizando manuales escolares utilizados en la etapa de obligatoriedad escolar en dos períodos: la Transición y los primeros años del siglo XXI. Se trata de establecer cambios y permanencias, lo que nos permitirá dar recomendaciones de cara a la confección y/o uso de este tipo de recurso en la escuela.

\section{Abstract}

Over the years, textbooks have dominated over other resources at school. Textbooks are also a conduit for the academic content that institutions want to deliver, a reflection of society in that the mainstream social attitudes, values and stereotypes and ideologies are reflected in their pages. It is a well-known fact that the established mindset is disseminated with them, hence shaping an overt and covert curriculum. Textbooks therefore reproduce the collective imagination dominated by a patriarchal society, one in which women play a second position and play traditional female roles. Altogether, it paints the essentialist female condition.

Post-Franco Spain put an end to dictatorial manners and now new social, economic and political reality should prevail and harmful sex inequality should have vanished too. Textbooks should replicate this new lifestyle. This paper presents a content analysis of textbooks, both of the illustrations and the text itself. We want to test if this change has taken place a tall, with a particular analysis of the economic culture. We therefore compare textbooks of the time right after the dictatorship, some forty years ago with the textbooks in use now at the turn of the century. We explore differences and similarities which may inspire new textbooks for the present time.

Palabras clave: Mujer, Economía, Manuales escolares, España democrática.

Keywords: Woman, Economy, Textbooks, Democracy, Spain. 


\section{INTRODUCCIÓN}

El objetivo principal de esta investigación es analizar y comparar el rol de la mujer relacionado con el ámbito económico transmitido en los manuales escolares de las áreas de Lengua Española y de Ciencias Sociales, utilizados en Educación Primaria durante la Transición (1975-1982) y la España actual (2006-2017). La relación entre mujer y cultura económica en el contexto español ha sido poco estudiada desde la historiografía, sobre todo si la vinculamos a la socialización obtenida a lo largo de los años de formación escolar obligatoria, que creemos que influyen en la elección profesional posterior. Esta ausencia de conocimiento resulta de gran interés para indagar en la construcción de la propia identidad femenina y su vinculación con la forma de entender el mundo y el plano económico; por lo que se ha convertido en un elemento de primer orden en el proyecto de investigación titulado «Economía, patriotismo y ciudadanía: La dimensión económica de la socialización política en los manuales escolares españoles desde el Tardofranquismo hasta la Transición» (EDU 2016-78143-R), financiado por el Ministerio de Economía y Competitividad (en el que la Dra. Guichot, es miembro del equipo investigador). Uno de sus objetivos fundamentales es detectar si hay discriminación sexista, en qué grado y de qué forma en el papel que se le atribuye al hombre y a la mujer en su contribución al desarrollo económico del país. De este modo, la presente investigación amplía dicho proyecto, examinado la evolución experimentada desde la Transición hasta nuestros días.

El principal motivo para centrarnos en el currículum escolar es que transmite unos modelos de masculinidad y feminidad jerarquizados que cambian dependiendo de la clase social y del momento histórico; tratándose de un factor de primer orden en la difusión y reproducción - de forma evidente o enmascarada- de estereotipos, roles de género y conductas discriminatorias hacia las mujeres (Moreno, 2006). Nuestra investigación se centra el currículum explícito y concretamente hemos analizado uno de los recursos didácticos por excelencia utilizados por el profesorado en el aula, el libro de texto. En este marco, diversos trabajos previos han descubierto manifestaciones de sexismo: en el tipo de lenguaje utilizado, en la omisión de personajes y logros femeninos, y en la infrarrepresentación y desvalorización de las mujeres (Garreta y Carega, 1987; Subirats y Tomé, 1992; Martín, 2006; Blanco, 2007; Llorca, 2007; Pérez y Gargallo 2007; López-Navajas, 2015). Además, en el ámbito académico se han hallado también diferentes tipos de estudios o materias con distintivo de género, según la valoración que emite la sociedad en función de su sexo (Bolívar y Hernández, 2005). Aparecen diferencias por género en la elección de unas carreras profesionales u otras, que no tendrían su origen en una menor capacitación real por sexo en un ámbito determinado, por ejemplo, debido a un menor rendimiento femenino en los estudios técnicos, sino que su origen radicaría en una renuncia voluntaria por parte de unos y otras, quienes deciden elegir ocupaciones con las que se identifica más su rol social (Moso, González, Vasconez y Sanguña 2017).

El sexismo en los manuales escolares puede manifestarse implícita o explícitamente. El sexismo explicito aparece cuando existe un gran desequilibrio entre el número de personajes masculinos y femeninos, cuando el lenguaje utilizado invisibiliza al sexo femenino, proporcionando una mayor importancia al varón, etc. El sexismo implícito muestra visiones estereotipadas de los personajes, omitiendo actitudes, comportamientos o actividades de uno de los sexos, con lo que se ofrecen modelos restringidos de identificación personal y social. Aunque no dejemos de lado el sexismo explícito, en nuestra investigación hemos querido desvelar principalmente el implícito, más difícil de diagnosticar, y para ellos nos basaremos en manuales de primaria, debido a que es un nivel mucho menos estudiado que la secundaria (Moreno, 1987; Blanco, 2000; Luengo y Blázquez, 2004; González, 2005: y López-Navajas, 2015) y que, sin embargo, fue obligatorio en el período de la Transición y, por supuesto, también lo es actualmente, lo que significa que es cursado por todos los niños y niñas. Además, la etapa de primaria es un periodo muy relevante en la construcción de la propia identidad personal, y se asocia a la atribución de roles, valores, espacios de actuación, etc., en relación al género (Flores, 2005).

\section{METODOLOGÍA}

La metodología empleada en esta investigación es de tipo mixta, es decir, une dos tipos de análisis y recogida de datos: cuantitativo y cualitativo; lo que posibilita enfrentar el problema desde

\footnotetext{
${ }^{1}$ Este trabajo se halla inserto en el Proyecto del Programa Estatal de I+D+i Orientada a los Retos de la Sociedad, cuya referencia es EDU 2016-78143-R.
} 
distintas perspectivas y mejorar la comprensión del fenómeno estudiado (Caro, García y Bezunartea, 2004). Consideramos que no es suficiente con cuantificar cuántas mujeres y cuantos hombres aparecen en los manuales escolares, ya que como sugiere Subirats (1993) las mujeres pueden aparecer, el problema es que se presenten asociadas a estereotipos y roles sexistas.

El marco de muestras utilizado comprende cuatro libros de texto, todos del nivel de quinto de la educación obligatoria (10 años): dos pertenecientes al área de Lengua Castellana, publicados en los años 1982 y 2011, correspondientes a las editoriales Everest y Anaya; y dos del área de Ciencias Sociales, de los años 1982 y 2015, de las editoriales Barcanova y Edebé.

\section{RESULTADOS Y CONCLUSIONES}

Tras la investigación realizada podemos afirmar que se ha producido un ligero progreso respecto a la inclusión de la perspectiva de género en los manuales escolares más recientes, en comparación con el periodo de la Transición. Actualmente existen medidas legislativas, políticas y sociales que abogan por la igualdad, encaminadas a evitar y prohibir la publicación de material escolar que contenga contenidos sexistas. A nuestro entender, aquí radica la principal razón por la que el sexismo en los libros de texto se haya visto reducido.

A pesar de ello, hemos podido observar que aún queda mucho camino por recorrer para lograr alcanzar una verdadera igualdad de género en los libros de texto que profesorado y alumnado manejan en las aulas y ello nos conmina a prestar especial atención a la selección de los manuales escolares que vayamos a utilizar en nuestras clases y a no cesar en dar llamadas de atención a las autoridades educativas para que no descuiden la vigilancia en el rechazo a cualquier contenido sexista en los mismos. Sin duda, los manuales escolares han sido, y continúan siendo hoy en día, el recurso mayormente utilizado en el proceso de enseñanza-aprendizaje y son, por tanto, uno de los caminos privilegiados a través de los cuales, los niños y las niñas acceden a los conocimientos que la sociedad considera «legítimos» y construyen su propia visión del mundo. No consintamos que las generaciones del siglo $\mathrm{XXI}$ se eduquen en una injusta discriminación sexista.

Los datos analizados y recopilados en la presente investigación guardan similitudes respecto a los obtenidos en investigaciones anteriores sobre la temática. A nivel de contenidos, observamos un aumento del número de personajes femeninos en los libros más actuales y se detecta que, además, en los manuales de Lengua Castellana dicha presencia aumenta frente al área de Ciencias Sociales. Aun así, el total de personajes analizados fueron 498, de los cuales tan solo 120 eran mujeres y 378 hombres; o, dicho de otro modo, más de un $75 \%$ de los personajes presentes en los libros de texto seleccionados se corresponden con el sexo masculino. Desglosando por períodos, en la Transición el total de personajes que aparecen en el contenido de los libros de texto fue de 267, de los cuales 53 eran mujeres, frente a 214 hombres. O, dicho de otro modo, más del $85 \%$ de los personajes que aparecen en los libros de texto de la Transición se corresponden a personajes masculinos, y solo un $13 \%$ femeninos. En el periodo actual, el total de personajes analizados en los contenidos fue 231, de los cuales 67 eran mujeres y 164 hombres. El porcentaje de personajes femeninos en esta etapa ronda el $23 \%$, por lo que podemos observar que la presencia de personajes femeninos en los libros de texto más actuales se ha incrementado en un $10.07 \%$ respecto a la etapa de la Transición.

Esta desigualdad de género presente en los libros de texto se hace todavía más acentuada si profundizamos en la autoría de las obras. Si desglosamos por períodos, el total de obras con autoría en el periodo de la Transición es de 101, entre las cuales aparecen 87 obras de autoría masculina y 14 femenina, esto es, un $6,3 \%$ de las obras son de autoría femenina. En el período actual, el total de obras con autoría es de 92, entre las cuales aparecen 77 obras de autoría masculina y 15 femenina, es decir, un $8,6 \%$ son de autoría femenina. Por consiguiente, en los libros de texto analizados observamos resultados alarmantes y demoledores, en los que del total de obras (193), se encuentran 164 autores y únicamente 29 autoras. En otras palabras, un $84.97 \%$ de media son obras de autoría masculina y si hacemos hincapié en el avance entre ambos períodos, ha sido tan solo del 2,3\% en cuanto a autoría femenina. Además, en el caso de los manuales de Ciencias Sociales de ambos periodos históricos, no encontramos ninguna obra de autoría femenina, lo que es realmente preocupante, al suponer una gran pérdida cultural. No olvidemos que en los libros de texto se seleccionan quiénes van a ser los referentes y el legado que se presenta tiene un único rostro: el masculino. Este modelo androcéntrico, en el que no hay voces femeninas, invita a preguntarnos si no ha habido escritoras en nuestra literatura, pensadoras en la historia, etc., que deban ser destacadas y estudiadas en los centros educativos. 
A nivel de contenido lingüístico, observamos algunos avances en los libros más actuales respecto al periodo de la Transición, especialmente en el lenguaje empleado. En nuestros resultados se observa un mayor compromiso por una utilización de un lenguaje más inclusivo, mientras que en el periodo anterior predominaba casi exclusivamente el uso del masculino como genérico. Este abuso del masculino para hacer referencia a ambos sexos, es lo que Moreno (1987) denuncia en su lectura crítica no-androcéntrica. En su investigación centrada en libros de texto de Historia de primer y tercer curso de Bachillerato Unificado Polivalente (BUP), observó cuáles de estas referencias aludían a mujeres, hombres o ambos. El total de referencias masculinas fue de 2.386, y por tanto un 99,0\%, frente a 25 referencias femeninas, que se corresponden con un $1,0 \%$. Así, se presenta un falso genérico, en el que lo que se habla sobre mujeres y hombres es bastante diferente y se revela una insignificante aparición femenina en el discurso de la historia. Además, nos lleva a plantearnos la siguiente cuestión y es hasta qué punto pueden las mujeres sentirse identificadas dentro de esta generalización. Aunque hayamos encontrado una menor utilización del masculino genérico, éste continúa siendo bastante frecuente. De este modo, señalamos que el español es un idioma que presenta multitud de posibilidades para nombrar adecuadamente lo femenino y darle el protagonismo, reconocimiento y visibilidad que se merece. De otra forma, estaríamos ocultando a la mujer tras un supuesto colectivo, que en la mayoría de los casos resulta ambiguo y descontextualizado, derivando en confusiones que tienden a asumir a dichos sujetos como masculinos.

A nivel de imágenes, en nuestra investigación se han analizado un total de 320 imágenes, de las cuales 52 aparecen sólo mujeres, frente a 179 en las que aparecen sólo hombres y 89 en las que aparecen ambos sexos, es decir, aproximadamente un $16 \%$ de las ilustraciones son las que representan únicamente al sexo femenino. Dicho porcentaje permanece prácticamente invariable entre los periodos históricos analizados y se corresponde con los resultados obtenidos por estudios previos como Lezcano (1977) o Luengo y Blázquez (2004). Profundizando en las imágenes contabilizamos 814 personajes representados, de entre ellos, 219 fueron mujeres y 595 hombres. Se observó que el número de mujeres representadas en las imágenes de los libros de texto actuales se ha incrementado ínfimamente, lo que ayuda a que aumente la visibilidad femenina.

Sin embargo, coincidimos con Subirats (1993) en que es importante reconocer que el principal problema se encuentra en el modo en el que aparecen representadas, es decir, si existe un modelo masculino y femenino estereotipado en el tipo de emociones, actitudes, espacios que ocupan, edades que presentan, actividades que realizan, etc. Centrándonos en el ámbito económico, observamos que en los libros más actuales continúa presentándose un número muy reducido de mujeres que obtienen una remuneración económica por su labor desempeñada, aunque destacamos que el porcentaje de mujeres que la reciben ha aumentado considerablemente desde la Transición (9.86\%) hasta la etapa actual $(20.01 \%)$. A su vez, lo más frecuente es encontrar a las mujeres principalmente en actividades del sector terciario, y destacamos como excepción el libro de texto de Ciencias Sociales de la época de la Transición, en el cual se encuentran representadas las mujeres en un mayor número de sectores económicos, frente al más actual de la misma área de conocimiento. Las actividades que suelen desarrollar las mujeres se encuentran repartidas especialmente entre el ámbito social y relacional y el doméstico. Además, nos llama la atención una clara diferencia entre las áreas de conocimiento estudiadas: en Lengua, ninguna mujer aparece representada en los sectores primario y secundario, pero, en Sociales, las mujeres aparecen en casi todos los sectores, como puede observarse en la Tabla 1.

Tabla 1. Porcentajes de los sectores económicos.

\begin{tabular}{|c|c|c|c|c|c|}
\hline Sectores económicos & Área & Sexo & Sector primario & Sector secundario & Sector terciario \\
\hline \multirow{6}{*}{ Transición } & \multirow{2}{*}{ Lengua } & Mujer & $0.0 \%$ & $0.0 \%$ & $100.0 \%$ \\
\hline & & Hombre & $24.1 \%$ & $0.0 \%$ & $75.9 \%$ \\
\hline & \multirow{2}{*}{ Sociales } & Mujer & $30 \%$ & $50 \%$ & $20 \%$ \\
\hline & & Hombre & $36.5 \%$ & $26.9 \%$ & $36.5 \%$ \\
\hline & \multirow{2}{*}{ Total } & Mujer & $15.0 \%$ & $25.0 \%$ & $60.0 \%$ \\
\hline & & Hombre & $30.3 \%$ & $13.5 \%$ & $56.2 \%$ \\
\hline \multirow{6}{*}{ Actual } & \multirow{2}{*}{ Lengua } & Mujer & $0 \%$ & $0 \%$ & $100 \%$ \\
\hline & & Hombre & $0 \%$ & $25 \%$ & $75 \%$ \\
\hline & \multirow{2}{*}{ Sociales } & Mujer & $13.3 \%$ & $0.0 \%$ & $86.7 \%$ \\
\hline & & Hombre & $7.5 \%$ & $2.8 \%$ & $89.6 \%$ \\
\hline & \multirow{2}{*}{ Total } & Mujer & $6.7 \%$ & $0.0 \%$ & $93.3 \%$ \\
\hline & & Hombre & $3.8 \%$ & $13.9 \%$ & $82.3 \%$ \\
\hline
\end{tabular}

Fuente: Elaboración propia. 
Por último, entre las actividades incluidas en el sector terciario, realizamos una clasificación pormenorizada en diferentes servicios como protección y seguridad, transporte, enseñanza, sanitario, etc. Un sector que permanece invariable en el tiempo es el ámbito de la protección y seguridad ya que en ninguno de los libros de texto actuales analizados encontramos mujeres que aparezcan desempeñando profesiones como policías, algo que puede favorecer la escasa presencia femenina en este sector. En la etapa de la Transición, las mujeres aparecían representadas en un $50 \%$ en ocupaciones vinculadas a la enseñanza. En cambio, en la etapa actual las mujeres están representadas en los libros examinados en un mayor número de servicios,como los de cargos públicos (30.8\%), y sorprendentemente no encontramos ninguna mujer dedicada a la enseñanza.

Los hombres no solo aparecen representados en un mayor número de ocasiones en actividades en las que reciben un salario, sino que, además, sus empleos son mucho más variados: la presencia masculina es omnipresente en todos los sectores profesionales. Observamos así una clara discriminación en el mundo laboral, en la que se presenta tanto una segregación horizontal, como vertical. Dichas afirmaciones se corresponden con las presentadas por Nieves Blanco (2000). En su investigación, de un total de 56 libros de texto de la ESO, se contabilizaron únicamente 26 ocupaciones desempeñadas por personajes femeninos, frente a 209 profesiones diferentes ejercidas por personajes masculinos. Los niños cuentan así con un número mucho más amplio de posibilidades y oportunidades profesionales, encuentran en los libros de texto referentes entre los que poder decidir y elegir lo que quieran ser. En cambio, las niñas apenas encuentran modelos con los que poder sentirse identificadas y las profesiones que se presentan suelen ser muy estereotipadas y reducidas al cuidado y a las labores del hogar; lo cual no se corresponde con el avance de las mujeres en la actualidad. Sin embargo, estudios recientes muestran que se encuentran ciertas diferencias entre el tipo de estudios que chicas y chicos eligen. Como señalamos más arriba, estas diferencias en la elección de unas carreras profesionales $u$ otras parece que no se deben a menor capacitación real de unos y otras en un ámbito determinado, sino a una decisión por optar por ocupaciones con las que se identifica más su rol social (Moso, González, Vasconez y Sanguña, 2017). Un motivo o razón que podría influir en esta decisión se encontraría en esta limitación profesional de las mujeres en los libros de texto.

En síntesis, los resultados y conclusiones derivadas de nuestra investigación, que pretendemos ir ampliando aumentando el tamaño de la muestra, al igual que los estudios anteriormente comentados, revelan el carácter androcéntrico de los libros de texto, en el que se reconoce una ausencia femenina en todos sus ámbitos y especialmente en relación a la aportación de la mujer en el desarrollo socioeconómico del país. Se hace evidente la importancia de continuar investigando y profundizando en los manuales escolares desde la perspectiva de género, ya que incluso en los más actuales persisten estereotipos anacrónicos que se refuerzan y manifiestan en dicho material didáctico y que se trasladan a la vida académica, profesional y personal de los futuros ciudadanos y ciudadanas.

\section{REFERENCIAS BIBLIOGRÁFICAS}

Arribas, J. (1982). Mensaje 5 Lengua Castellana. La Coruña, España: Everest.

Bello, C., Bernal, T., Lluva, C., Magarzo, J. L., y Zaragoza, P. (2011). Lengua 5 Educación Primaria. Madrid, España: ANAYA. Blanco, N. (2000). El sexismo en los materiales educativos de la E.SO. Instituto Andaluz de la Mujer. Sevilla, España.

Blanco, N. (2007). Análisis de materiales curriculares, en A. Vega. (Ed.), Mujer y educación una perspectiva de género (pp.105-115). Málaga, España: Ediciones Aljibe.

Bolívar, A. B., y Hernández, R. (2005). Identificación de los estereotipos sexistas en el currículo oculto del colegio de bachiIlerato Dolores María Ucrós de Soledad. Revista Psicogente, 8(13), 9-16.

Caro, F., García, M., y Bezunartea, O. (2014). La metodología mixta de investigación aplicada a la perspectiva de género. Palabra Clave, 17(3), 828-853.

Escolano, A. (2001). El libro escolar como espacio de memoria. En G. Ossenbach, y M. Somoza. (Eds.), Los manuales escolares como fuente para la historia de la educación en América Latina (pp. 35-45). Madrid, España: Universidad Nacional de Educación a Distancia.

Fernández, M., y García, L. (1982). Etnos 5 EGB Ciencias Sociales. Barcelona, España: Barcanova. 
Flores, R. (2005). Violencia de género en la escuela: sus efectos en la identidad, en la autoestima y en el proyecto de vida. Revista Iberoamericana de Educación, 38, 67-86.

Garreta,N., y Careaga, P. (1987). Modelos masculinos y femeninos en los textos de EGB. Madrid, España: Instituto de la Mujer.

González, M. (2005). ¿Tienen sexo los contenidos de la educación física escolar? Transmisión de estereotipos de sexo a través de los libros de texto en la etapa secundaria. Revista Internacional de Medicina y Ciencias de la Actividad Física y el Deporte, 5 (18), 77-88.

Lezcano, S. (1977). Tontas útiles desde la EGB. Cuadernos de psicología, 11-12, 4046.

Llorca, M. (2007). Flexibilidad y rigidez en los roles de género, en A. Vega. (Ed.), Mujer y educación una perspectiva de género (pp.79-89). Málaga, España: Ediciones aljibe.

López-Navajas, A. (2015). Las mujeres que nos faltan: análisis de la ausencia de las mujeres en los manuales escolares (Tesis doctoral). Universitat de València, Valencia.

Luengo, M. R. y Blázquez, F. (2004). Género y libros de texto: un estudio de estereotipos en las imágenes. Mérida, España: Instituto de la Mujer de Extremadura.

Martín, R. (2006). El sexismo en los libros de texto. En M. Nuñez. (Ed.), Educación y Mujeres II: materiales de trabajo (pp.7595). Sevilla, España. Editorial Arcibel.

Mola, J. L., et al. (2015). Ciencias Sociales 5 Educación Primaria. Barcelona, España: Edebé.

Moreno, A. (1987). El arquetipo viril protagonista de la historia: ejercicios de lectura no androcéntrica. Barcelona, España: Editorial La Sal.

Moreno, A. (2006). Más allá del género: aportaciones no-androcéntricas a la construcción de un humanismo plural, en C. Rodríguez. (Ed.), Género y currículo aportaciones del género al estudio y práctica del currículo (pp.103-126). Madrid, España: Ediciones Akal.

Moso, G. M., González, A. O., Vasconez, B. y Sanguña, E. (2017). El sexismo en la elección de carreras técnicas y propuesta de sensibilización sobre la equidad de género. Ciencias Pedagógicas, 3 (5), 341-373.

Pérez, C., y Gargallo, B. (2007). Sexismo y estereotipos de género en los textos escolares, en Actas XXVI Seminario Interuniversitario de Teoría de la Educación: Lectura y Educación, Universitat Autónoma de Barcelona, Lloret de Mar, 626-636.

Ruíz, L., y Vallejo, C. (1999). ¿Qué queda del sexismo en los libros de texto? Revista Complutense de Educación, 10(2), 125-145.

Subirats, M. (1993). El sexismo en los libros de texto: análisis y propuesta de un sistema de indicadores. Madrid, España: Instituto de la Mujer.

Subirats, M. y Tomé, A. (1992). La educación de niños y niñas. Recomendaciones institucionales y marco legal. Barcelona: Institut de Ciènces de l'educació.universitat autónoma de Barcelona. 